\title{
Community Health Workers as Innovators: Methods and Results from a Tele- Education Pilot for Community Health Workers in Detroit, Michigan
}

\author{
Tyler Prentiss, BA \\ Henry Ford Health System \\ tprenti1@hfhs.org \\ Dana Parke, BA \\ Henry Ford Health System \\ dparke1@hfhs.org \\ Monica White, MPH \\ Henry Ford Health System \\ mwhite11@hfhs.org
}

\author{
Ilyssa Tamler, BA \\ Henry Ford Health System \\ ilyssatamler@gmail.com
}

\author{
Mohan Tanniru, $\mathrm{PhD}$ \\ School of Business Administration \\ Oakland University \\ tanniru@oakland.edu
}

Kimberlydawn Wisdom, MD, MS

Henry Ford Health System

Kwisdom1@hfhs.org

\author{
Alexander Plum, MPH, CHES \\ Henry Ford Health System \\ aplum2@hfhs.org
}

Michele Harrison Sears
Henry Ford Health System
mharris3@ @fhs.org

Linda Kaljee, $\mathrm{PhD}$

Henry Ford Health System

lkaljee1@hfhs.org

\begin{abstract}
Community health workers (CHWs) have played an important role in improving the health of underserved populations in resource-limited settings. CHWs are trusted in communities that they serve, and are often able to see solutions to community problems that outside persons cannot. Solutions need to be low cost and easily accessible, and address the knowledge gaps among CHWs through appropriate training. Utilizing information technology solutions can be key to increasing access to knowledge for these community agents. This paper outlines the methods and results from a pilot study of the Community Health Innovator Program performed in Detroit, Michigan with a group of community health workers in basic grant-writing training, utilizing an information technology platform. The results will be discussed as a larger response to growing issues in global health and how such platforms can be used and adapted in response to ever-evolving global health challenges.
\end{abstract}

\section{Introduction}

Increasingly, eHealth and mHealth applications have been developed worldwide for community health workers (CHWs) to use in their daily practices [1,2], on health topics ranging from maternal health [3], TB and HIV/AIDS treatment [4], and cardiovascular disease [5]. CHWs play a vital role in resource-limited settings, as they provide an important link between healthcare providers and the needs of the community. Results from different community health worker programs around the world have shown an increase in the number of patients counseled, patient enrollment in health programs, and the number of visits that patients make [6]. In many areas, access to information technology solutions is limited, thus low-cost yet high-impact solutions are necessary. Community health workers often do not receive training on non-health related topics due to limited funding, time, and resources.

CHWs are motivated to serve their communities to the best of their abilities and are sometimes chosen to be community liaisons and provide an important link between communities and resources [7-9]. In nearly all settings, the $\mathrm{CHW}$ is regarded as a community leader who is held in high esteem and highly trusted in the communities he or she serves $[10,11]$. In many underserved communities, health outcomes are often defined by external, non-community members and organizations [12,13]. This, in turn, makes improving health outcomes difficult when the solution to the problem is not owned or innovated by the community itself [14]. This idea is at the core of the Community Health Innovator Program (CHIP), a program that aims to empower community health workers through information technology solutions. The importance of additional training has been expressed to the project team through many ongoing conversations with global community stakeholders.

This paper will outline the model of the Community Health Innovator Program and its utilization of IT strategies for improved outcomes in global health, including the results of a pilot study performed in Detroit, Michigan. Section 2 will look at the basis of the Community Health Innovator Program and its broader use for community health workers in a knowledge sharing model. Section 3 will explore the idea of "reverse innovation" and its relationship to the idea exchange between community health workers and mentors from different disciplines. Section 4 will 
discuss the technology platform designed to support the CHIP program and Section 5 describes the pilot study. Section 6 will provide the results from the pilot study and Section 7 discusses these results. Section 8 concludes and provides directions for the future.

\section{Community Health Workers as Innovators}

With the goal of leveraging the power of community health workers, the authors and other stakeholders formed a multidisciplinary group (later known as the "CHIP team") consisting of experts in public health, information technologies, community health, social sciences, business management, and governmental affairs. The CHIP team researched the literature as well as conducted focus group discussions and other types of communications with CHWs and other stakeholders.

Several themes emerged from this research. First, a need for multidisciplinary training was identified, to allow CHWs to innovate and implement broader health solutions in their communities. A desire for additional professional development opportunities has been expressed by community health workers in several areas [15-17]. Second, due to limited time, funding, and resources, in-person training for $\mathrm{CHWs}$ in international settings poses a challenge; consequently, an IT platform provides one solution to support knowledge sharing and training activities. Indeed, electronic training has been shown to result in cost savings [18]. Finally, as mentioned earlier, communities are more receptive to health behavior interventions when they are implemented and owned by the community itself [14].

Based on this knowledge, the team developed the Community Health Innovator Program as a possible solution to increase the impact that community health workers can make in their communities. CHIP is an electronic- and mobile-health supported knowledge sharing program, where community health workers receive training on topics that were identified as needed to address global community health challenges, as well as best practices across regions.

The idea of CHIP is not to replace traditional community health worker training, but rather to supplement it by offering non-health topics including business management, grant-writing, and other fields with relevance to resource-limited settings. These trainings aim to foster a culture of empowerment within the participating $\mathrm{CHWs}$ to address health issues within their own communities through innovative thinking and implementation.

Further, CHIP utilizes a team of selected "Mentors" who are available to $\mathrm{CHW}$ participants (or, "Innovators") throughout the duration of the program. Mentors will be experts in their field with whom
Innovators can work and learn from. The project team will identify both Mentors and Innovators in each country in order to have Mentors who can accurately understand nuances and challenges of the CHW's communities. Besides direct training; IT platform supports peer to peer communication so best practices can be shared and possibly adapted by others facing similar challenges. When technologies are exported from developing regions into more developed areas, it is termed "reverse innovation." The concept of reverse innovation and its relevance to the Community Health Innovator Program is explored in detail in the following section.

Through a framework built on interconnectivity, CHIP utilizes information technology and the everincreasing spread of knowledge to enable community actors to originate ideas that will have the potential to transform not only their own communities, but other communities globally. The Community Health Innovator Program plans to help nurture ideas that can be adapted to flourish in other similar settings. Innovators will work with their peers, who reside in different regions, to export their techniques and programs with other $\mathrm{CHWs}$ who face similar problems in their community. The final stage of the CHIP curriculum will involve connections between the Innovator, the Mentor, and Innovators from additional sites to move solutions to identified health challenges into the implementation phase. Such a knowledge exchange can occur in multiple ways among the different stakeholder groups, synchronously or asynchronously in dyadic or triadic exchanges. For these reasons, a synchronous video conference framework developed in early research [19] and shown in Figure 1 was adopted to support CHIP. As will be discussed later, only stage 1 is implemented for pilot testing phase; other stages are to be added incrementally.

\section{Reverse Innovation}

First coined by Govindarajan and Trimble, reverse innovation describes the flow of ideas from lower to higher income settings [20]. In their model applying reverse innovation to the health care sector, DePasse and Lee practically define reverse innovation as "learning from and investing in poorer settings as one way to tackle problems in wealthier settings that require out-ofthe-box solutions" [21]. With rising healthcare costs and increasingly complex, multi-determinant health challenges, the need for creativity and innovative thinking has never been higher.

Govindarajan and Trimble point out how resourcelimited settings look for "value for many" instead of "value for money," suggesting that innovators in these 
settings must think radically about how to achieve acceptable quality at a very low cost. While underdeveloped infrastructure allows creators a blank canvas with which to develop technological inventions, these settings are also barriers that reinforce the need for high value and low cost solutions.

Community health workers from low-income areas who represent populations with overwhelming health needs are well situated to think innovatively about ways to confront and overcome those needs.[22] Their contexts prime their involvement in schemes like CHIP which afford them supplementary training and skills to facilitate their innovative thinking and designing. In these ways, CHWs represent a promising cadre of frontline 'reverse innovators.' Working at the grassroots level, CHWs ideate, advocate, and respond to the needs expressed by the populations they represent.

The Community Health Worker model is, itself, a reverse innovation at work in the US healthcare landscape. CHWs originated in China in the 1960s as "barefoot doctors" responsible for the care of farmers in very remote communities.[23] Globally, over 1.3 million CHWs provide diverse healthcare services; in the United States, more and more health systems are incorporating them because of their trusted identities and their potential to provide lower cost and high impact healthcare delivery.

Everett Rogers, the author of the pioneering work Diffusion of Innovation describes five criteria that must exist before an innovation is accepted: they must be better than alternatives, relevant to local contexts, easily communicated, highly visible and trusted, and easily tested [24]. DePasse and Lee also utilize the Diffusion of Innovation theory in their model of reverse innovation in health care[21], which will be discussed further in reference to the pilot study results. CHWs, because of their close contact to the thought-leaders of their communities, are perfectly situated to know and create options that are superior to current approaches that fail to satisfy the needs of their neighbors. Their position also affords them the trust and visibility to test these innovations authentically and constructively. In these ways, CHWs are perfectly situated to participate in the reverse innovation process as creators, diffusers, and influencers. The next sections will demonstrate how CHWs fulfilled these roles through the technology platform used to pilot test the first stage of CHIP implementation.

\section{Technology Platform}

The CHIP Portal is at the core of the intervention and has to be designed with sensitivity to the needs of community health workers around the world. CHIP must serve the needs of underserved populations globally, who generally have lower access and less familiarity with technology. To address these challenges, early discussion on content and prototype structure of the portal were facilitated with input from various members of the study team and experts familiar with information technologies and portal design. These discussions illuminated several key factors being considered, including visual appeal, multiple language support, and providing different methods to share knowledge and provide training. Participants must be able to use the website with minimal help from support staff in order to reduce the time burden. The website must help users build profiles in order to allow Innovators to select Mentors who can support their needs, while allowing Mentors to identify where they can make the most contribution.

While not utilized in the pilot study, a mobile phone-based application is currently under development for use by CHIP participants. The need for mobile phone technology has been increasing as its availability and use continues to penetrate developing markets. The global penetration of mobile phones in 2013 was reported at $96 \%$ [25] and mHealth solutions are continually developed at a rapid pace. A 2013 study identified $215 \mathrm{mHealth}$ studies in the clinicaltrials.gov database, with 40 alone being added during a six-month period [26]. However, with the increase in mHealth applications, appropriate measures must be taken into consideration to ensure that the information is accurate, necessary, and accessible by residents of low- and middle-income areas, where it has the potential to be most useful. It is essential to consider issues such as bandwidth and Internet connection and speed if CHIP is to provide a useful user experience to those in underserved areas. During initial CHIP discussions, participants expressed a desire for a mobile-phone based tool in an effort to improve accessibility of content.

For the pilot study, the team built the CHIP training website with a version of Moodle (Version 3.0, Moodle Ltd Pty, Perth, Australia). The Moodle website housed the evaluations, tests, PowerPoints, static videos, necessary documents, and any aspects necessary for implementation of the pilot study. A screenshot of the website used is shown in Figures 2-4.

\section{Pilot Study}

Prior to implementation of the pilot study, several focus group discussions with community health workers were undertaken to gauge their interest level in the CHIP model and identifying priority multidisciplinary topic areas. These focus group discussions took place in GrosMorne and Jérémie, Haiti, as well as in Detroit, Michigan. Throughout these discussions, participants were enthusiastic about the idea of receiving additional 
training in fields not traditionally available within a community health worker training curriculum. Training in grant writing was deemed particularly important, so that $\mathrm{CHWs}$ can leverage their position and knowledge to apply for further resources to implement solutions to improve health in their communities.

Study participants were recruited by study team staff from community health worker programs that operate in and around the Detroit metropolitan area, through the Michigan Community Health Workers Alliance (MiCHWA), which serves populations around the state of Michigan. To be considered for eligibility in the study, participants had to be an active, part- or fulltime community health worker serving a community in the Detroit metropolitan area. The Detroit area was selected as the pilot site as it is a low-income area within in the United States where community health workers face similar challenges to those in underserved areas globally. Fifteen participants ultimately took part in the one-day grant-writing training session in March 2016.

Five modules relating to grant-writing basics were drafted and designed by the study team, including experts in grant-writing from several institutions. The one-day training was built to have quizzes and short hands-on activities after each module. Each module is followed by a quiz and successive modules are only presented when a participant completes the quiz following the preceding module. This ensures consistency in the learning from prior concepts. A preand post-quiz was built for participants in order to gauge information uptake throughout the course of the day. An evaluation of the website was also designed for program participants to assess several categories important in the use of the web-portal, including ease of navigation, modes of communication needed in connecting the project staff, using either the website or synchronous videoconferencing technology, navigational issues faced by program participants, and usefulness of the content built for the course. The final activity was a Letter of Intent (LOI) writing exercise, which utilized skills that the participants learned throughout the day. The submitted LOIs were reviewed by grant-writing experts and returned to the CHWs with advice and comments regarding where to go next with their ideas.

The training was delivered using three different methods: 1) a static PowerPoint, which participants read at their own pace; 2) an embedded YouTube video, recorded by a member of the study team for use during the training, and; 3) a live videoconferencing session presented to the assigned group of study participants by a member of the study team on the day of the training. Participants were randomly assigned to one of these delivery methods in order to measure group differences between delivery methods.
Post-training focus group discussions were also incorporated into the day in order to gather more information of what participants thought about the training. The training was conducted at a single site (project team's campus) in order to cover all the information in a single day, to have participants use similar technology to minimize errors, and ensure that participants completed their training. Future trainings will attempt to replicate the training as close as possible to mimic the CHIP innovators engagement protocol as they engage in their community health work. Participants were informed of the days' activities and informed consent was received.

The pilot study protocol was reviewed and approved by the Henry Ford Health System Institutional Review Board.

\section{Results}

Results of the selected quizzes and evaluations from the grant-writing training were extracted from the Moodle site and inserted into Excel spreadsheet for further data analysis.

14 out of 15 participants $(93.3 \%)$ were female. 10 out of $15(66.6 \%)$ participants hold an associate's degree or higher. The average participant has held a position as a community health worker for 12.3 years.

Before initiating the training session, the prior knowledge of the participants was tested in order to determine the knowledge attained as a result of CHIP. On the grant writing pre-test, the average score received was 9.2 out of 12. Each of the three different groups (PowerPoint, YouTube video, and videoconferencing) scored a 9.2 average, indicating an equal starting point.

Upon completion of each of the five training modules, participants were given a post-test, which was identical to the pre-test, and demonstrated a $12.8 \%$ improvement, averaging 10.375 out of 12 (Table 1). The scores of each of the three training methods were also assessed for the pre- and post-tests, and those participants in the group that received training via PowerPoint showed the greatest improvement, demonstrating a $19.6 \%$ increase, while the group that received training via videoconferencing showed the smallest improvement with a $3.2 \%$ increase (Table 2 ).

In addition, after each of the five learning objectives, short quizzes were administered to assess the knowledge acquired throughout the training modules. On both the "First Things First" quiz, which tested the general knowledge about grants, and the "What to Do Before You Write [an LOI]" quiz, participants scored an average of 3.93 out of 5, or $78.6 \%$. On the "Request for Proposals" quiz, participants scored an average of 4.79 out of 5, or $95.7 \%$. Many, however, had difficulty with the "Writing a Letter of Intent" quiz, scoring a 2.69 out 
of 5 , or $53.8 \%$; yet, they scored much higher on the "Fine-Tuning the LOI" quiz with 3.33 out of 4 , or $83.3 \%$ (Figure 1). The scores of each of the three training methods were also assessed, yet there was no correlation between method of administration and quiz/test scores (Figure 2).

Overall, participants' feedback was overwhelmingly positive. A post-survey, which allowed participants to review CHIP, was administered in two parts. The first part of the survey was done utilizing a Likert scale and asked participants to answer questions using a scale from 1 through 4 , with 4 being the most positive. The second part asked for written comments to qualitative questions posed by the study team. In every category, from whether or not the CHIP training was useful to the participant's career, to the website format and level of difficulty to use, to whether or not the participant would participate in another similar training program, an overall score of 3.5 or higher was noted.

Many said that they "enjoyed the method utilized" and that the training "was informative" and "useful." There was also positive feedback from most participants saying they would like to take these training modules again, suggesting an array of future topics, and all said that they would positively recommend this training program to others. One participant responded, "Please call me every time you have a training that I' $m$ eligible for."

\section{Discussion}

Because three different teaching methods were utilized, many of the comments received throughout the day were assessed independently. Those who received the videoconferencing method had positive comments about the training method. Those who received training via a YouTube video said that the video was not all that useful and that it would have been more beneficial "to have a person discuss the different topics [more generally] while [the participants] have the information in front of [them]," rather than "have a person read the slides" to the participants. Finally, those that received training via the PowerPoint presentation articulated that it would have been desirable to have a presenter and that they would take this training again if they received a different style of training.

The response to the post-training survey regarding the types of delivery methods indicate that live videoconferencing would be the most preferred delivery method for electronic content. However, the potential logistical issues with presenting a global curriculum could pose challenges to the amount of live videoconferencing able to be communicated. Challenges with time differences, scheduling, and further logistical issues may complicate the ability for facilitators to perform an involved videoconferencing curriculum. Also, as noted, those who received the training via PowerPoint scored higher on the posttraining assessment. Thus, while preferences may be for videoconferencing as a more interpersonal means of delivering information, self-teaching is also an effective medium. Internet connectivity problems, and other issues may lead to heightened difficulties with videoconferencing solutions. However, as the price lowers and ease-of-access grows, live videoconferencing between Mentors and Innovators will be integrated into further CHIP trainings. Results from the small sample size show that roughly all delivery methods had similar scores on the quizzes throughout the curriculum. However, more data would be needed to make a definitive conclusion on the efficacy of one delivery method vs. another. Therefore, elements of all three delivery methods will be utilized as additional training content in developed.

Participants also addressed their concerns and suggested changes in the post-survey. One raised concerns that it was difficult to maneuver the website and training program in general due to a lack of computer literacy. Technological literacy is a concern that must be addressed in future iterations of the program, as large swaths of the global population do not often have advanced technological literacy seen in many developed areas. Another felt that it was "too much for a first timer" to do all at once and would have preferred for it to have been spread out over the training.

Two particularly useful suggestions were also proposed. One participant thoughtfully suggested that "the activity questions not just be at the end of the PowerPoint, but also where the activity will be submitted." The second pointed out that people need to have an email address to create an account, and that some cannot access their email outside of their workplace, or on study computers because of Internet restrictions, and this should be considered moving forward with CHIP.

As noted in the results section, 14 out of 15 participants in the training were female. While this is a high number, it has been shown that generally, community health workers around the world are majority female, estimated as high as a 70 percent female workforce [27].

By working in sites throughout the world, opportunities for innovations from one part of the world taking root in another arise. Rogers' Diffusion of Innovation theory describes five sections of adopters throughout society: innovators, early adopters, early majority, late majority, and laggards. In Depasse and Lee's model for reverse innovation in health care settings[21], they utilize these adopter categories to 
explain the spread of innovations from low-income areas to high-income areas. Across settings, when the early adopters in a low-income area accept an innovation, the innovators in a high-income area tend to start adoption and the innovation moves throughout the five adopter categories according to the five factors of the Diffusion of Innovation theory. CHIP slots into this ecosystem by providing opportunities for innovators worldwide to work with other innovators, both in lowand high-income areas. This allows for innovations created through the program to proliferate to further areas, as most of the participants in the program will fall into the innovator or early adopter class. This crosscultural work can also address one of the barriers perceived through reverse innovation, when stakeholders in high-income areas dismiss proven ideas based on the country or region of origin.[28] When talked about with the participants in a post-session focus group, participants expressed a desire to look to other sites for solutions in their communities and to learn from them through the work being done worldwide.

One of the prevailing themes of discussion in the post-training focus group discussions was the idea of intellectual property and idea theft. As the participants worked through the training, they were made to come up with and write an idea that would be submitted for feedback. Several participants brought up the worry of how to keep their idea safe from intellectual property theft. Many of the participants cited this as a concern in the post-training focus group discussion. Further education in this topic is planned as a follow-up activity to the pilot training, in collaboration with legal experts from a local university. Additional information will be made to participants about the complexities of intellectual property as it related to grant-writing and submission.

Limitations with the data include a lack of participants in the pilot study to make fully accurate assumptions about long-term results and next steps. In addition, there was some attrition throughout the day, preventing some participants of the training from taking all assigned quizzes. However, with the results of the pilot study, the CHIP model will be exported to different topic areas where CHWs can make a difference, including topics such as entrepreneurship, intellectual property rights, and others, as suggested by community health workers. Additional training sites are also necessary to determine the effectiveness of the training platform globally. Additional limitations came from unfamiliarity with the website from some study participants who had difficulties with the web-based training. Future trainings will continue refining and improvement of the web-based portal for ease of access and use by participants and future development of the mobile-based application for wider use in underserved populations, including making the content useful and easy to navigate for those with low technological literacy.

\section{Conclusion}

The pilot study in Detroit, Michigan and repeated discussions with community health workers in additional underserved areas has allowed the project team to explore areas such as how to better tailor the content and approach to serve its target population. As seen from the discussions post-training, continued interest and commitment by CHIP participants are necessary for improved health outcomes. Though not formal leaders in a given community, community health workers informally support their communities and often have the trust of the community members. With the tools to help enact change in their own communities, the Community Health Innovator Program, with additional training and shared knowledge, can allow a community to adapt and change to today's health care challenges.

The role of information technology in future global health challenges cannot be understated. As technology progresses and innovative solutions continue to become more prevalent in underserved areas globally, innovative $\mathrm{m}$ - and eHealth solutions to emerging health problems must be utilized effectively in order to ensure that solutions are useful and sustainable for the targeted populations. The CHIP platform and framework will be used at other project sites to foster ideas and allow for community members and interested Mentors globally to interact and potentially implement community-driven ideas. Future pilot tests will include the mobile phone application in support of training. These efforts in leveraging technology must avoid the pitfall of not providing "essential" and "actionable, offline guidance" [29]. In a 2014, study, it was found that out of a sample size of 1700 mHealth projects, less than ten provided useful information that could be used offline by people in underserved populations [30]. While many of these applications are often used in the United States and other developed areas, it underscores the necessity for mHealth solutions that can be used globally and in populations that require continuous Internet connectivity to work. The project team will continue work with its mobile developer in order to provide actionable content that can be utilized by the broadest possible base in areas where CHIP can make the highest impact.

Additionally, global-local exchange must be harnessed throughout these care delivery and support processes. These exchanges can help expedite solutions that may not have been possible without multiple community stakeholders collaborating on an issue. The rise of synchronous communication globally through 
previous IT solutions has enabled people around the world to work to collaborate to solve health problems. As community health workers and further community members are empowered to enact their own solutions to problems faced in their communities, the concept of reverse innovation will continue to emerge as implementations are adapted for use in diverse areas.

The Community Health Innovator Program takes these ideas and works to enhance existing efforts of community health workers through use of a system designed to allow communication between community health workers, mentor teams, and other community stakeholders in order to create solutions that are community-driven and well-suited for local populations. Further development of the program will ensure that CHIP will serve as an important global health IT solution to pressing global health challenges.

\section{References}

[1] Braun R, Catalani C, Wimbush J, Israelski D. Community health workers and mobile technology: a systematic review of the literature. PLOS ONE [Electronic Resource]. 2013;8(6):e65772.

[2] Agarwal S, Perry HB, Long LA, Labrique AB. Evidence on feasibility and effective use of mHealth strategies by frontline health workers in developing countries: systematic review. Tropical medicine \& international health : TM \& IH. 2015;20(8):1003-14.

[3] Little A, Medhanyie A, Yebyo H, Spigt M, Dinant GJ, Blanco R. Meeting community health worker needs for maternal health care service delivery using appropriate mobile technologies in Ethiopia.[Erratum appears in PLoS One. 2014;9(1). doi:10.1371/annotation/fedf94d2-cf4e-494c8828-85861ce282a5]. PLoS ONE [Electronic Resource]. 2013;8(10):e77563.

[4] Odendaal WA, Lewin S. The provision of TB and HIV/AIDS treatment support by lay health workers in South Africa: a time-and-motion study. Hum Resour Health. 2014;12:18.

[5] Surka S, Edirippulige S, Steyn K, Gaziano T, Puoane T, Levitt N. Evaluating the use of mobile phone technology to enhance cardiovascular disease screening by community health workers. Int J Med Inf. 2014;83(9):648-54.

[6] Vaughan K, Kok MC, Witter S, Dieleman M. Costs and cost-effectiveness of community health workers: evidence from a literature review. Hum Resour Health. 2015;13:71. [7] Ludwick T, Brenner JL, Kyomuhangi T, Wotton KA, Kabakyenga JK. Poor retention does not have to be the rule: retention of volunteer community health workers in Uganda. Health Policy Plan. 2014;29(3):388-95.

[8] Rahman SM, Ali NA, Jennings L, Seraji MH, Mannan I, Shah R, Al-Mahmud AB, Bari S, Hossain D, Das MK, Baqui $\mathrm{AH}, \mathrm{El}$ Arifeen S, Winch PJ. Factors affecting recruitment and retention of community health workers in a newborn care intervention in Bangladesh. Hum Resour Health. 2010;8:12. [9] Mpembeni RN, Bhatnagar A, LeFevre A, Chitama D, Urassa DP, Kilewo C, Mdee RM, Semu H, Winch PJ, Killewo J, Baqui AH, George A. Motivation and satisfaction among community health workers in Morogoro Region, Tanzania: nuanced needs and varied ambitions. Hum Resour Health. 2015;13:44.

[10] Kowitt SD, Emmerling D, Fisher EB, Tanasugarn C. Community Health Workers as Agents of Health Promotion: Analyzing Thailand's Village Health Volunteer Program. J Community Health. 2015;40(4):780-8.

[11] Mishra A. 'Trust and teamwork matter': community health workers' experiences in integrated service delivery in India. Glob Public Health. 2014;9(8):960-74.

[12] Merzel C, D'Afflitti J. Reconsidering community-based health promotion: promise, performance, and potential. Am J Public Health. 2003;93(4):557-74.

[13] Cheadle A, Beery W, Wagner E, Fawcett S, Green L, Moss D, Plough A, Wandersman A, Woods I. Conference report: community-based health promotion--state of the art and recommendations for the future. Am J Prev Med. 1997;13(4):240-3.

[14] Chambers R. Participatory Rural Appraisal (PRA): Challenges, Potentials and Paradigm* World Development. 1994;22(10):1437-54.

[15] Li L, Zhang Z, Sun Z, Zhou H, Liu X, Li H, Fan L, Coyte PC. Relationships between actual and desired workplace characteristics and job satisfaction for community health workers in China: a cross-sectional study. BMC Fam Pract. 2014;15:180.

[16] Wennerstrom A, Johnson L, Gibson K, Batta SE, Springgate BF. Community health workers leading the charge on workforce development: lessons from New Orleans. J Community Health. 2014;39(6):1140-9.

[17] Zhang M, Yang R, Wang W, Gillespie J, Clarke S, Yan F. Job satisfaction of urban community health workers after the 2009 healthcare reform in China: a systematic review.

International Journal for Quality in Health Care.

2016;28(1):14.

[18] Sissine M, Segan R, Taylor M, Jefferson B, Borrelli A, Koehler M, Chelvayohan M. Cost Comparison Model: Blended eLearning versus traditional training of community health workers. Online Journal of Public Health Informatics. 2014;6(3):e196.

[19] Park Y, Tanniru M, Khuntia J. Designing an Effective Social Media Platform for Health Care with Synchronous Video Communication. American Journal of Information Technology. 2014;4(1).

[20] Govindarajan V, Trimble C. Reverse innovation: Create far from home, win everywhere. Boston, MA: Harvard Business Review Press; 2012.

[21] Depasse JW, Lee PT. A model for 'reverse innovation' in health care. Global Health. 2013;9:40.

[22] Harris M. Community health workers: an opportunity for reverse innovation. Lancet. 2013;382(9901):1326-7.

[23] Zervos J, Parke D. The Next Generation of Community Health Worker Programs: Huffington Post; 2015 [cited 2016]. Available from: http://www.huffingtonpost.com/johnm-zervos/the-next-generation-of-co_1_b_7152994.html. [24] Rogers E. Diffusion of Innovations. New York, NY: Simon and Schuster; 2003.

[25] International Telecommunication Union. ICT Facts and Figures. Geneva, Switzerland: International

Telecommunication Union; 2013. 
[26] Labrique A, Vasudevan L, Chang LW, Mehl G. H_pe for mHealth: more "y" or "o" on the horizon? Int J Med Inform. 2013;82(5):467-9.

[27] Lehmann U, Sanders D. Community health workers:

What do we know about them? In: Evidence and Information for Policy DoHRfH, editor. Geneva, Switzerland: World Health Organization; 2007. p. 1-34.

[28] Harris M, Weisberger E, Silver D, Macinko J. 'They hear "Africa" and they think that there can't be any good services' - perceived context in cross-national learning: a qualitative study of the barriers to Reverse Innovation. Globalization Health. 2015;11.

[29] Royston G, Hagar C, Long LA, McMahon D,

Pakenham-Walsh N, Wadhwani N, m HWG. Mobile healthcare information for all: a global challenge. Lancet Glob Health. 2015;3(7):e356-7.

[30] Hagar C, Kartzinel H. Healthcare Information For All By 2015: Preliminary findings and future direction.

Information Development. 2016;32(3):354-61. 
Table 1. Overall averages for pilot study participants

\begin{tabular}{|c|c|c|c|c|c|c|c|}
\hline & $\begin{array}{l}\text { Quiz } 1 \\
\text { First } \\
\text { Things } \\
\text { First } \\
\text { Quiz } \\
\text { (Out of } \\
\text { 5) }\end{array}$ & $\begin{array}{l}\text { Quiz: } \\
\text { What to } \\
\text { Do } \\
\text { Before } \\
\text { You } \\
\text { Write } \\
\text { Quiz } \\
\text { (Out of } \\
\text { 5) }\end{array}$ & $\begin{array}{l}\text { Quiz: The } \\
\text { Request for } \\
\text { Proposals } \\
\text { Quiz (Out of } \\
\text { 5) }\end{array}$ & $\begin{array}{l}\text { Quiz: Writing } \\
\text { a Letter of } \\
\text { Intent Quiz } \\
\text { (Out of 5) }\end{array}$ & $\begin{array}{l}\text { Quiz: Fine- } \\
\text { Tuning the } \\
\text { LOI Quiz (Out } \\
\text { of } 4 \text { ) }\end{array}$ & $\begin{array}{l}\text { Quiz: } \\
\text { Grant } \\
\text { Writing } \\
\text { Pre-Test } \\
\text { (Out of } \\
\text { 12) }\end{array}$ & $\begin{array}{l}\text { Quiz: } \\
\text { Grant } \\
\text { Writing } \\
\text { Post-Test } \\
\text { (Out of } \\
\text { 12) }\end{array}$ \\
\hline AVERAGE: & 3.93 & 3.93 & 4.785714286 & 2.692307692 & 3.333333333 & 9.2 & 10.375 \\
\hline & $78.6 \%$ & $78.6 \%$ & $95.7 \%$ & $53.8 \%$ & $83.3 \%$ & $76.7 \%$ & $86.5 \%$ \\
\hline
\end{tabular}

Table 2. Quiz averages by delivery method

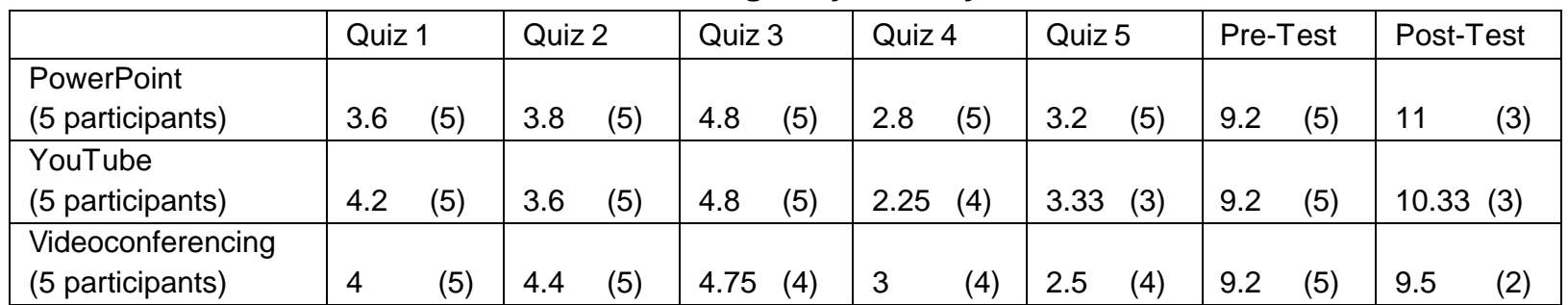

*Note: number in parentheses signifies the number of participants who took each quiz

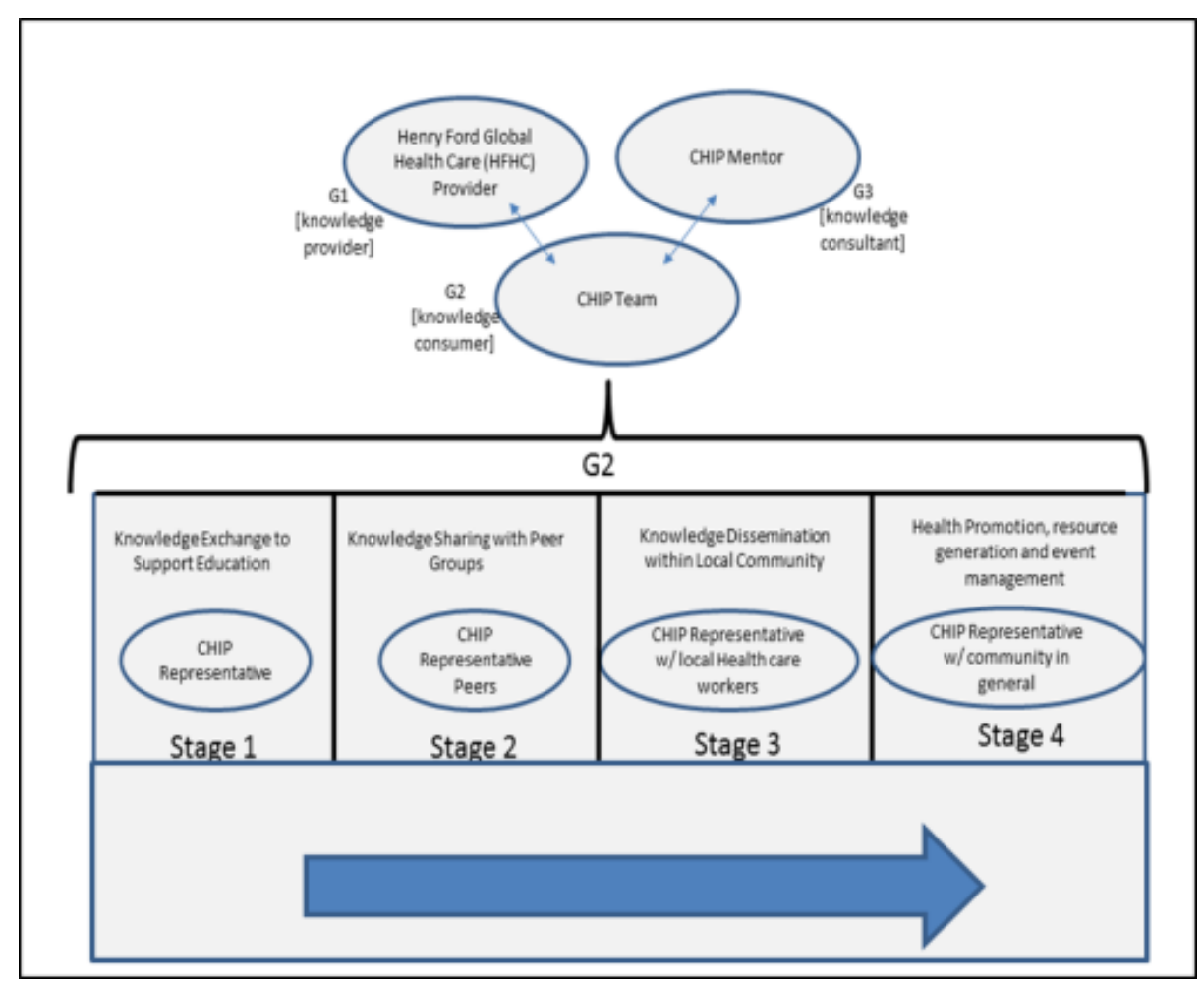

Figure 1. Model for developing support for CHIP team members 
Grant Writing Basics: Pewter
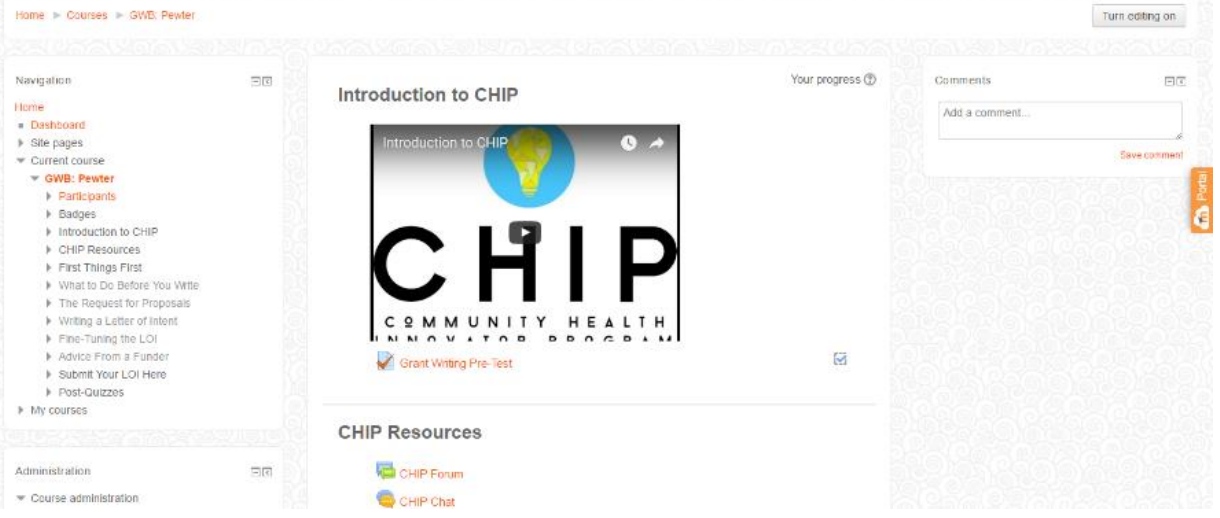

Figure 2. CHIP Main Navigation Page

Grant Writing Basics: Pewter
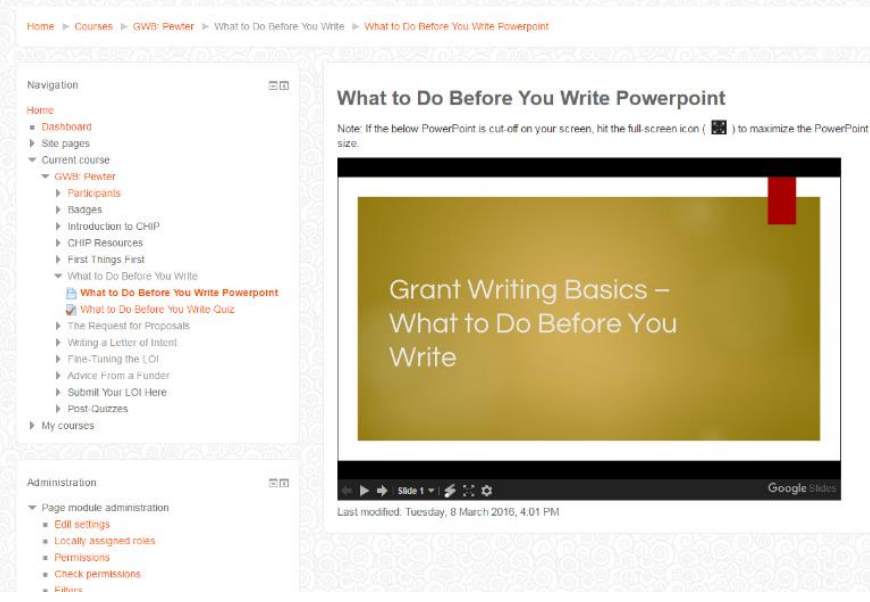

Figure 3. Sample CHIP PowerPoint page

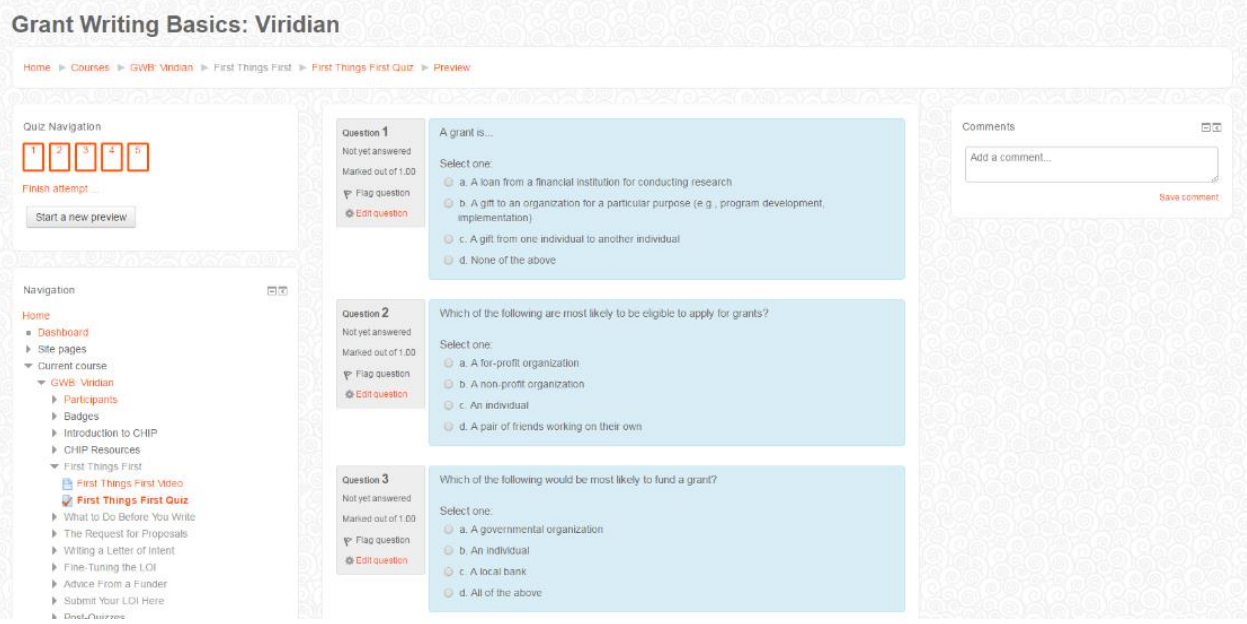

Figure 4. Sample CHIP Quiz Page 